\title{
Antibiotic susceptibility of invasive Neisseria meningitidis isolates from 1995 to 2008 in Sweden-the meningococcal population remains susceptible
}

\author{
SARA THULIN HEDBERG, PER OLCÉN, HANS FREDLUND \& MAGNUS UNEMO
}

15 From the National Reference Laboratory for Pathogenic Neisseria, Department of Laboratory Medicine, Clinical Microbiology, Örebro University Hospital, Örebro, Sweden

Abstract

The susceptibility to 7 antibiotics was determined for all Swedish invasive Neisseria meningitidis isolates from 1995 to 2008 ( $N=$ 717). In general, these remain highly susceptible to the antibiotics recommended for use. Accordingly, penicillin $G$ remains effective for the treatment of invasive meningococcal disease and ciprofloxacin appropriate for prophylaxis.

\section{Introduction}

The continuing increase in antibiotic resistance in many bacterial pathogens is a serious public health threat worldwide. Neisseria meningitidis, causing meningitis and septicaemia, has been an exception, in that it has generally remained susceptible to the antibiotics used for treatment and prophylaxis. However, during the last decade, there have been several reports of $\mathrm{N}$. meningitidis isolates with intermediate susceptibility to penicillins [1-4], and earlier, exceedingly rare $\beta$-lactamase producing isolates were described $[5,6]$. Intermediate susceptibility/resistance to ciprofloxacin [7-12] and resistance to rifampicin [13-15] have also been reported from several countries. Furthermore, although rare, there have been reports of chloramphenicol-resistant $\mathrm{N}$. meningitidis isolates from Australia, France and Vietnam $[16,17]$. Resistance to ceftriaxone is claimed to have been identified and was reported from India [18]. These strains have, however, not been further examined, comprehensively phenotypically and genetically characterized, and/or confirmed by an independent laboratory [19].

During recent decades, Sweden has had a low incidence of invasive meningococcal disease, i.e. an annual incidence of 0.5 to 1.1 cases per 100,000 inhabitants during 1995 to 2008 (Swedish Institute for Infectious Disease Control; http:// smittskyddsinstitutet.se/in-english/statistics/meninzgococcal-infection). Any comprehensive description and analysis of the antibiotic susceptibility of Swedish N. meningitidis isolates over a longer time period has hitherto never been performed.

The aims of the present study were to describe and analyse the antibiotic susceptibility of all Swedish invasive N. meningitidis isolates from 1995 to 2008 , to identify any longitudinal trends in the susceptibility and/or resistance, and to briefly discuss effective antibiotics for treatment and propzhylaxis.

\section{Materials and methods}

All Swedish invasive N. meningitidis isolates cultured and characterized by the Swedish Reference Laboratory for Pathogenic Neisseria, Örebro University Hospital, Sweden, from 1995 to 2008 ( $N=$ 717; from blood (438), cerebrospinal fluid (266), joint fluid (12), unspecified (1)) were included in the study. The corresponding patients were $52 \%$ males (mean age $24 \mathrm{y}$, median age $18 \mathrm{y}$, range $0-91 \mathrm{y}$ ) and $48 \%$ females (mean age $32 \mathrm{y}$, median age $20 \mathrm{y}$, range 0-96 y). The isolates were of serogroup B $(n=391 ; 55 \%), \mathrm{C}(n=204 ; 28 \%), \mathrm{Y}(n=79 ; 11 \%)$, W-135 $(n=33 ; 5 \%), 29 \mathrm{E}(n=2), \mathrm{A}(n=1), \mathrm{X}$ $(n=1), \mathrm{Z}(\mathrm{n}=1)$, and non-groupable (NG; $n=5)$. The minimum inhibitory concentrations (MICs) of 
0 Table I. Susceptibility of all Swedish invasive Neisseria meningitidis isolates from 1995 to $2008(N=717)$ to 7 different antibiotics.

\begin{tabular}{lccccccc}
\hline Antibiotic & $\begin{array}{c}\text { Breakpoint } \\
\mathrm{S} \leqslant / \mathrm{R}>\end{array}$ & $\begin{array}{c}\text { MIC range } \\
(\mathrm{mg} / \mathrm{l})\end{array}$ & $\begin{array}{c}\mathrm{MIC}_{50} \\
(\mathrm{mg} / \mathrm{l})\end{array}$ & $\begin{array}{c}\mathrm{MIC}_{90} \\
(\mathrm{mg} / \mathrm{l})\end{array}$ & $\begin{array}{c}\text { Susceptible } \\
\%\end{array}$ & $\begin{array}{c}\text { Intermediate } \\
\text { susceptible } \%\end{array}$ & $\begin{array}{c}\text { Resistant } \\
\%\end{array}$ \\
\hline Penicillin $\mathrm{G}$ & $0.094 / 1^{\mathrm{a}}$ & $0.006-1$ & 0.047 & 0.094 & 91.4 & 8.6 & 0 \\
Penicillin V & $1 / 1^{\mathrm{b}}$ & $<0.016-6$ & 0.25 & 0.75 & 98 & 0 & 2 \\
Cefotaxime & $0.12 / 0.12^{\mathrm{b}}$ & $<0.002-0.047$ & 0.003 & 0.006 & 100 & 0 & 0 \\
Chloramphenicol & $2 / 4^{\mathrm{c}}$ & $0.094-6$ & 0.75 & 1.5 & 99.6 & 0.3 & 0.1 \\
Ciprofloxacin $_{\text {Rifampicin }}$ & $0.03 / 0.25^{\mathrm{c}}$ & $<0.002-0.012$ & 0.004 & 0.006 & 100 & 0 & 0.1 \\
Sulfadiazine $^{\mathrm{d}}$ & $0.25 / 1^{\mathrm{c}}$ & $<0.002-0.38$ & 0.012 & 0.047 & 99.9 & 8 & 0.1 \\
& $1 / 4^{\mathrm{c}}$ & $0.19->256$ & 256 & $>256$ & 8 & 25.5 & 66.5 \\
\hline
\end{tabular}

10

MIC, minimum inhibitory concentration.

${ }^{a}$ Breakpoints previously described by Taha et al. [2], based on a combination of identified penicillin G MIC and presence/absence of penA mosaic allele.

${ }^{b}$ Breakpoints in accordance with the Swedish Reference Group for Antibiotics (http://www.srga.org).

cBreakpoints proposed by the European Meningococcal Disease Society [25].

$15{ }^{\mathrm{d}}$ Breakpoints for sulfisoxazole were used, which when compared to sulfadiazine, using Etest, displayed similar MIC distribution (data not shown).

penicillin $\mathrm{G}$, penicillin $\mathrm{V}$, cefotaxime, chloramphenicol, ciprofloxacin, rifampicin, and sulfadiazine (used as an epidemiological marker) were determined for all isolates using the Etest method (AB Biodisk, Solna, Sweden) on Mueller-Hinton agar supplemented with $5 \%$ heated ('chocolated') defibrinated horse blood, at $37^{\circ} \mathrm{C}$ in $5 \% \mathrm{CO}_{2}$ for $16-18 \mathrm{~h}$. The breakpoints used are shown in Table I. All isolates were also tested for $\beta$-lactamase production using nitrocefin discs (AB Biodisk, Solna, Sweden).

\section{Results}

The results of the antibiotic susceptibility testing are summarized in Table I. In brief, all isolates (100\%) were $\beta$-lactamase-negative and highly susceptible to cefotaxime (MIC $\leqslant 0.047 \mathrm{mg} / \mathrm{l}$ ) and ciprofloxacin $(\mathrm{MIC} \leqslant 0.012 \mathrm{mg} / \mathrm{l})$. Mainly all isolates $(99.9 \%)$ were susceptible to rifampicin, i.e. only 1 serogroup $\mathrm{B}$ isolate from 2001 displayed intermediate susceptibility (MIC $0.38 \mathrm{mg} / \mathrm{l}$ ). With regard to chloramphenicol, 1 isolate $(0.1 \%)$ was resistant (serogroup B from 1996; MIC $6 \mathrm{mg} / \mathrm{l}$ ) and 2 isolates $(0.3 \%)$ displayed intermediate susceptibility (one serogroup C from 2000 and 1 serogroup B from 2003). In total, intermediate susceptibility to penicillin G $\left(\right.$ pen $^{\mathrm{I}}$ ) was observed in $8.6 \%$ of the isolates, and $59 \%$ of the pen ${ }^{\mathrm{I}}$ isolates were of serogroup B. Overall, the pen ${ }^{\mathrm{I}}$ phenotype was most prevalent in serogroup $\mathrm{W}-135$ isolates ( $18 \%$ of all W-135 isolates), followed by serogroup B (10\%) and C (7\%). Two percent of the isolates were resistant to penicillin $\mathrm{V}$, and $50 \%$ of these were serogroup B isolates. The proportion of isolates displaying intermediate susceptibility to penicillin $\mathrm{G}$ varied between $4 \%$ and $18 \%$ during the trend towards a less susceptible meningococcal population (Table II). The percentage of sulfadiazine resistance varied from $52 \%$ to $81 \%$ per $\mathrm{y}$.

\section{Discussion}

The Swedish population of invasive N. meningitidis isolates remains highly susceptible to the antibiotics recommended, both for treatment and prophylaxis. For penicillin $\mathrm{G}$, in some $y$ an increase of isolates with intermediate susceptibility could be observed, however there was no obvious longitudinal trend towards a less susceptible meningococcal population for penicillin G or any of the other antibiotics. Compared to studies from other European countries, such as France [20], Portugal [21] and Italy [22], the antibiotic susceptibility patterns were similar for cefotaxime, chloramphenicol, ciprofloxacin, rifampicin, and sulfadiazine. However, in France and Portugal the proportions of isolates with intermediate susceptibility to penicillin $\mathrm{G}$ were substantially higher than in Sweden: $31.7 \%$ in France (MIC $\geqslant 0.125 \mathrm{mg} / \mathrm{l}$ ) [20] and $24.6 \%$ in Portugal (MIC $>0.06 \mathrm{mg} / \mathrm{l}$ ) [21]. A very high percentage of pen ${ }^{\mathrm{I}}$ isolates was also reported in a Spanish study (55.3\%) [23]. In all these 3 countries the prevalence of pen ${ }^{\mathrm{I}}$ isolates was significantly higher among serogroup C isolates than serogroup B isolates. Accordingly, the high prevalence of pen ${ }^{\mathrm{I}}$ in these countries is at least partly due to the high prevalence of serogroup $\mathrm{C}$ isolates belonging to serotype $2 \mathrm{~b}: \mathrm{P} 1.5,2$, which is a phenotype previously shown to be associated with intermediate penicillin susceptibility [2]. In fact, in Italy the proportion of $\mathrm{pen}^{\mathrm{I}}$ isolates significantly increased (from $7.5 \%$ to $27.4 \%$ ) as a result of the introduction of this serogroup C clone [24]. Thus, in Sweden the relatively low level of the pen ${ }^{\mathrm{I}}$ phenotype in general, and in serogroup $\mathrm{C}$ in particular, might at 
0 Table II. Susceptibility to penicillin G among all Swedish invasive Neisseria meningitidis isolates recovered during $1995-2008(N=717)$.

\begin{tabular}{|c|c|c|c|c|c|c|}
\hline $\mathrm{Y}$ & $\begin{array}{l}\text { MIC range } \\
(\mathrm{mg} / \mathrm{l})\end{array}$ & $\begin{array}{l}\mathrm{MIC}_{50} \\
(\mathrm{mg} / \mathrm{l})\end{array}$ & $\begin{array}{l}\mathrm{MIC}_{90} \\
(\mathrm{mg} / \mathrm{l})\end{array}$ & $\begin{array}{l}\text { Susceptible \% } \\
(\leqslant 0.094 \mathrm{mg} /)^{\mathrm{a}}\end{array}$ & $\begin{array}{l}\text { Intermediate } \\
\text { susceptible \% }\end{array}$ & $\begin{array}{l}\text { Resistant \% } \\
(>1 \mathrm{mg} /)^{\mathrm{a}}\end{array}$ \\
\hline 1995 & $0.012-0.19$ & 0.032 & 0.094 & 94 & 6 & 0 \\
\hline 1996 & $0.012-0.25$ & 0.032 & 0.094 & 95 & 5 & 0 \\
\hline 1997 & $0.016-0.25$ & 0.047 & 0.094 & 90 & 10 & 0 \\
\hline 1998 & $0.006-0.5$ & 0.047 & 0.094 & 90 & 10 & 0 \\
\hline 1999 & $0.016-0.19$ & 0.047 & 0.064 & 96 & 4 & 0 \\
\hline 2000 & $0.023-0.25$ & 0.047 & 0.094 & 93 & 7 & 0 \\
\hline 2001 & $0.008-0.25$ & 0.047 & 0.094 & 95 & 5 & 0 \\
\hline 2002 & $0.016-0.25$ & 0.047 & 0.19 & 86 & 14 & 0 \\
\hline 2003 & $0.016-0.19$ & 0.047 & 0.125 & 88 & 12 & 0 \\
\hline 2004 & $0.012-0.38$ & 0.064 & 0.19 & 82 & 18 & 0 \\
\hline 2005 & $0.012-0.19$ & 0.064 & 0.094 & 94 & 6 & 0 \\
\hline 2006 & $0.016-1$ & 0.064 & 0.125 & 89 & 11 & 0 \\
\hline 2007 & $0.016-0.25$ & 0.047 & 0.19 & 88 & 12 & 0 \\
\hline 2008 & $0.012-0.125$ & 0.047 & 0.064 & 95 & 5 & 0 \\
\hline
\end{tabular}

MIC, minimum inhibitory concentration.

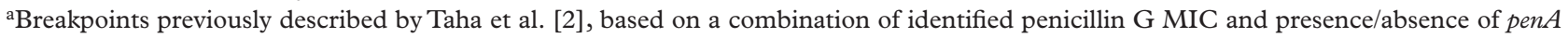
mosaic allele.

20

least partly be explained by the low prevalence of $\mathrm{C}: 2 \mathrm{~b}: 5,2$ meningococci.

An additional explanation for the lower level of intermediate susceptibility and resistance observed among Swedish invasive $\mathrm{N}$. meningitidis isolates might be the relatively low usage of antibiotics in Sweden compared to countries in Southern Europe (data from European Surveillance of Antimicrobial Consumption, available at: http://www.esac.ua.ac.be/

30 main. aspx?c $=*$ ESAC2\&n=50103). Most important, no treatment failure of invasive meningococcal disease using the recommended penicillin $G$ treatment has yet been identified in Sweden. Also globally these are extremely rare, most of them have not been

35 appropriately clinically and microbiologically confirmed and accordingly cannot be considered as conclusive. Thus, in Sweden intravenous penicillin G remains effective for the treatment of invasive meningococcal disease. Furthermore, ciprofloxacin remains appropriate for prophylaxis of invasive meningococcal disease. However, antibiotic susceptibility testing remains crucial to perform, i.e. in order to confirm adequate choice of antibiotic(s) for the treatment of invasive meningococcal disease as well as to timely

45 identify and monitor any emergence of new resistance in N. meningitidis. In addition, extended-spectrum third-generation cephalosporins, such as ceftriaxone and cefotaxime (if Listeria monocytogenes is suspected or cannot be excluded, e.g. intra-

50 venous amoxicillin needs to be administered in addition) and meropenem, which at present are also investigated at the Swedish Reference Laboratory for Pathogenic Neisseria, are effective and especially useful when the etiological agent of the bacterial meningitis has not been species-confirmed.

\section{Acknowledgements}

This study was supported by grants from the Örebro County Council Research Committee and the Foundation for Medical Research at Örebro University Hospital, Örebro, Sweden.

Declaration of interest: The authors have no conflict of interest to declare.

\section{References}

[1] Oppenheim BA. Antibiotic resistance in Neisseria meningitidis. Clin Infect Dis 1997;24(Suppl 1):S98-101.

[2] Taha MK, Vàzquez JA, Hong E, Bennett DE, Bertrand S, Bukovski $S$, et al. Target gene sequencing to characterize the penicillin G susceptibility of Neisseria meningitidis. Antimicrob Agents Chemother 2007;51:2784-92.

[3] Thulin S, Olcén P, Fredlund H, Unemo M. Total variation in the pen $A$ gene of Neisseria meningitidis: correlation between susceptibility to $\beta$-lactam antibiotics and penA gene heterogeneity. Antimicrob Agents Chemother 2006;50: 3317-24.

[4] Vázquez JA, Enriquez R, Abad R, Alcalá B, Salcedo C, Arreaza L. Antibiotic resistant meningococci in Europe: any need to act? FEMS Microbiol Rev 2007;31:64-70.

[5] Dillon JR, Pauzé M, Yeung KH. Spread of penicillinaseproducing and transfer plasmids from the gonococcus to Neisseria meningitidis. Lancet 1983;1:779-81.

[6] Botha P. Penicillin-resistant Neisseria meningitidis in southern Africa. Lancet 1988;1:54.

[7] Alcalá B, Salcedo C, de la Fuente L, Arreaza L, Uría MJ, Abad R, et al. Neisseria meningitidis showing decreased susceptibility to ciprofloxacin: first report in Spain. J Antimicrob Chemother 2004;53:409.

[8] Centers for Disease Control and Prevention (CDC). Emergence of fluoroquinolone-resistant Neisseria meningitidisMinnesota and North Dakota, 2007-2008. MMWR Morb Mortal Wkly Rep 2008;57:173-5. 
[9] Chu YW, Cheung TK, Tung V, Tiu F, Lo J, Lam R, et al. A blood isolate of Neisseria meningitidis showing reduced susceptibility to quinolones in Hong Kong. Int J Antimicrob Agents 2007;30:94-5.

[10] Corso A, Faccone D, Miranda M, Rodriguez M, Regueira M, Carranza C, et al. Emergence of Neisseria meningitidis with decreased susceptibility to ciprofloxacin in Argentina J Antimicrob Chemother 2005;55:596-7.

[11] Skoczynska A, Alonso JM, Taha MK. Ciprofloxacin resistance in Neisseria meningitidis, France. Emerg Infect Dis 2008;14:1322-3.

[12] Strahilevitz J, Adler A, Smollan G, Temper V, Keller N, Block C. Serogroup A Neisseria meningitidis with reduced susceptibility to ciprofloxacin. Emerg Infect Dis 2008;14:1667-9.

[13] Rainbow J, Cebelinski E, Bartkus J, Glennen A, Boxrud D, Lynfield R. Rifampin-resistant meningococcal disease. Emerg Infect Dis 2005;11:977-9.

[14] Stefanelli P, Fazio C, La Rosa G, Marianelli C, Muscillo M, Mastrantonio P. Rifampicin-resistant meningococci causing invasive disease: detection of point mutations in the rpoB gene and molecular characterization of the strains. J Antimicrob Chemother 2001;47:219-22.

[15] Taha MK, Zarantonelli ML, Ruckly C, Giorgini D, Alonso JM. Rifampin-resistant Neisseria meningitidis. Emerg Infect Dis 2006;12:859-60.

[16] Galimand M, Gerbaud G, Guibourdenche M, Riou JY, Courvalin P. High-level chloramphenicol resistance in Neisseria meningitidis. N Engl J Med 1998;339:868-74.

[17] Shultz TR, Tapsall JW, White PA, Ryan CS, Lyras D, Rood JI, et al. Chloramphenicol-resistant Neisseria meningitidis containing catP isolated in Australia. J Antimicrob Chemother 2003;52:856-9.

[18] Manchanda V, Bhalla P. Emergence of non-ceftriaxone-susceptible Neisseria meningitidis in India. J Clin Microbiol 2006;44:4290-1.

[19] Nicolas P, Manchanda V, Bhalla P. Emergence of nonceftriaxone-susceptible Neisseria meningitidis in India. J Clin Microbiol 2007;45:1378; author reply.

[20] Antignac A, Ducos-Galand M, Guiyoule A, Pirès R, Alonso JM, Taha MK. Neisseria meningitidis strains isolated from invasive infections in France (1999-2002): phenotypes and antibiotic susceptibility patterns. Clin Infect Dis 2003;37:912-20.

[21] Ferreira E, Dias R, Caniça M. Antimicrobial susceptibility, serotype and genotype distribution of meningococci in Portugal, 2001-2002. Epidemiol Infect 2006;134:1203-7.

[22] Mastrantonio P, Stefanelli P, Fazio C, Sofia T, Neri A, La Rosa G, et al. Serotype distribution, antibiotic susceptibility, and genetic relatedness of Neisseria meningitidis strains recently isolated in Italy. Clin Infect Dis 2003;36:422-8.

[23] Arreaza L, de La Fuente L, Vázquez JA. Antibiotic susceptibility patterns of Neisseria meningitidis isolates from patients and asymptomatic carriers. Antimicrob Agents Chemother 2000;44:1705-7.

[24] Stefanelli P, Fazio C, Neri A, Sofia T, Mastrantonio P. Emergence in Italy of a Neisseria meningitidis clone with decreased susceptibility to penicillin. Antimicrob Agents Chemother 2004;48:3103-6.

[25] Vázquez JA. Resistance testing of meningococci: the recommendations of the European Monitoring Group on Meningococci. FEMS Microbiol Rev 2007;31:97-100. 


\section{Author Query Sheet}

Date 14-09-09

Journal SINF

Article No 429442

Article Title Antibiotic susceptibility of invasive Neisseria meningitidis isolates from 1995 to 2008 in Sweden - the meningococcal population remains susceptible

Author Name SARA THULIN HEDBERG, PER OLCÉN, HANS FREDLUND \& MAGNUS UNEMO

You are requested to reply to the queries raised below and to incorporate the answers on these proofs. Thank you.

\begin{tabular}{|l|l|l|}
\hline $\begin{array}{l}\text { Page } \\
\text { Number }\end{array}$ & \multicolumn{1}{|c|}{ Query Details } & $\begin{array}{l}\text { Author's } \\
\text { Reply }\end{array}$ \\
\hline & [AQ1] Reference 25 is not cited in the text. Please advise. & \\
\hline
\end{tabular}

